\title{
Suicide prevention and developing countries
}

Murad M Khan

J R Soc Med 2005;98:459-463

Globally, approximately one million people kill themselves every year. ${ }^{1}$ The World Health Organization (WHO) has declared suicide a major global public health problem and called on member states to devise and implement national suicide prevention strategies.

While suicide prevention is receiving increased attention in many developed countries, it remains largely ignored in developing countries, where a number of factors impede the implementation of successful preventive programmes.

\section{METHODOLOGY}

For the purposes of this article WHO's Mortality Database which lists the suicide rates of reporting countries was examined. ${ }^{2}$ The database lists the country, latest year of reporting and the male and female suicide rates. 'Developing countries' refers to low and middle income countries and includes most countries of Africa, Asia and South America. Key articles relating to suicide in these countries were examined.

\section{TRENDS IN GLOBAL SUICIDES}

Global suicide rates have shown a steady increase over the last 50 years and are projected to increase to 1.53 million by the year 2020. ${ }^{1}$ This is despite significant advancements in recognition and treatment of depression and other mental disorders, the introduction of more effective and safer psychotropics (including anti-depressants) and improvement in mental health services in many countries. In countries like Finland and England suicide prevention programmes have successfully lowered suicide rates. ${ }^{3,4}$

Why then have global suicide rates continued to rise? Part of the answer may lie in the fact that while there have been gains in suicide prevention in developed countries it has been offset by huge increases in suicides in many developing countries, such as China and India. ${ }^{5}$

\section{GLOBAL SUICIDE STATISTICS}

Incidences of suicide are usually reported as rates per 100000 . Thus countries with rates of more than 30/ 100000 (e.g. Sri Lanka, Lithuania, Latvia) are considered

Department of Psychiatry, Aga Khan University, Stadium Road, PO Box 500, Karachi 74800, Pakistan

Email: murad.khan@aku.edu high rates countries; those with rates between 10-29/ 100000 (e.g. China, Slovenia, Japan) as middle rates countries and those with rates less than 10/100000 (e.g. Egypt, Jordan) as low rates countries. Rates, however, do not always reflect the true extent of the problem. For example, China has suicide rates of about 25/100000, which places it in the middle range but has the highest number of people-287000, who kill themselves annually. 6

Similarly, India has a rate of $10-11 / 100000$ but is second only to China in the actual number of people (110 000) who kill themselves. ${ }^{7}$ To put this in perspective, the total numbers of suicides in the four top ranking European countries - Lithuania, Latvia, Estonia and the Russian Federation - is less than the total number of suicides in India. In Brazil, suicide rates increased by $21 \%$ between 1980 and 2000 and is currently at 4/100000 (similar to most South American countries) which in real numbers is almost 8000 individuals. ${ }^{8}$ Pakistan, an Islamic country with traditionally few suicides, has seen a dramatic increase in suicide incidences over the last few years, from a few hundred to more than 3000 in $2003 .{ }^{9}$ Yet the country neither collects national suicide statistics nor reports them to WHO. Therefore when global suicide statistics are compiled or prevention programmes planned, countries like Pakistan are rarely taken into account.

\section{Reporting suicide mortality statistics to WHO}

According to the WHO Mortality Database $85 \%$ of suicides in the world occur in low and middle income countries, though data are unavailable for $73 \%$ of these countries. ${ }^{3}$ Overall there are no data on suicide for more than half of the world's countries, most of which are developing countries in Asia, Africa and South America. Although data from African countries are lacking, there are isolated reports which indicate that suicidal behaviour occurs in these countries as well — studies have been published from Tanzania, ${ }^{10}$ Nigeria, ${ }^{11}$ Zimbabwe, ${ }^{12}$ Uganda, ${ }^{13}$ Egypt, ${ }^{14}$ and Ethiopia. ${ }^{15}$ One of the emerging causes of suicidal behaviour in African countries is HIV/AIDS, which needs to be recognized and managed effectively. ${ }^{16}$

The non-reporting countries also include more than 50 countries where the majority of the population is Muslim, including those with populations in excess of 100 million such as Pakistan, Indonesia and Bangladesh. Suicide also 
occurs in all these non-reporting countries but, due to a variety of religious, legal and cultural factors, data collection and reporting is largely neglected.

\section{Developing countries: problems of data collection}

Suicide is no longer a criminal offence in any developed country but continues to be so in many developing countries, especially in many Islamic countries. ${ }^{9}$ Religious and social factors also continue to influence the diagnosis and registering of suicides. Families do not disclose the true nature of the act, for fear of harassment by police and/or social stigma. Instead they claim it to be either an accident or in some cases, a homicide. ${ }^{9}$

The stigma of mental disease and psychiatric helpseeking further compounds the problem, leading to underreporting of suicides, which may be as high as 30\% to $100 \%{ }^{1}$

\section{A 'REDUCTIONIST' MODEL OF SUICIDE}

Suicide reports from developing countries frequently highlight interpersonal relationship problems, domestic disputes and financial problems as the underlying cause of most suicides. ${ }^{17,18}$ Mental illness is rarely mentioned or is implicated in only a small number of suicides. Many of these reports are based on police or forensic medicine data, neither of which examine the psychological factors involved in suicides.

This approach has given rise to a 'reductionist model' of suicide that portrays the suicide victim in a developing country as an impulsive individual who over-reacts to personal setbacks and in an emotional fit ingests an easily accessible substance, e.g. organophosphate pesticide. With poor medical facilities for resuscitation there is a high ingestion to fatality ratio.

This model holds the individual responsible for his/her actions, emphasizing only the immediate proximal factors (e.g. a row with significant other), while ignoring important distal factors (e.g. depression that may be related to adverse social factors) that form the groundwork on which proximal factors act.

Recent studies of suicides from Taiwan and India using psychological autopsy method found mental illness to be present in $97-100 \%$ and $88 \%$ of victims, respectively. ${ }^{19,20}$

A relative lack of psychological sophistication among families and the investigating agencies, an avoidance of stigma attached to mental illness, and limited treatment resources are factors that have led to underestimations of psychiatric illness that predispose to suicide in developing countries.

\section{WOMEN, MARITAL STATUS AND SUICIDAL BEHAVIOUR}

Many studies of common mental disorders, deliberate self harm (DSH) and suicide which have come from developing countries highlight the over-representation of women, particularly young married women in these studies. ${ }^{21-24}$ In South India, suicide rates amongst young women were reported as 148/100000, making it one of the highest in the world. ${ }^{25}$ The male to female ratio in suicides is also much narrower - in China they are reversed. ${ }^{6}$ These studies suggest that, unlike the West where marriage is protective, in many developing countries it is a significant source of stress for women leading to higher psychiatric morbidity and suicidal behaviour.

Factors associated with higher psychiatric morbidity and suicidal behaviour in women in developing countries include early age at marriage, lack of autonomy in choosing male partner (arranged marriage), pressure to have children early in marriage (in many cases for a male offspring), economic dependence on husband and the joint family system. Domestic violence is also a serious problem in developing countries. ${ }^{26}$ Under these circumstances, the young married woman's position is severely compromised, making her vulnerable to psychiatric morbidity and suicidal behaviour.

\section{DEVELOPING COUNTRIES' PRIORITIES}

Many developing countries in Asia, Africa and South America are struggling with poverty alleviation, low literacy rates and high population growth. Communicable diseases and maternal and child health take precedence over noncommunicable diseases. Mental health has very low priority in these situations.

Crucially, many of these countries do not have established political processes that underpin progress in the social and health sectors. Many are governed by autocratic regimes, with little accountability of their policies. Health and social sectors receive only a small fraction of the national budget. Few have a separate mental health budget. For example, in Pakistan, only $0.7 \%$ of the gross domestic product (GDP) is allocated for health (mental health is estimated to be $1 \%$ of annual health budget) compared to $4.6 \%$ for defence. ${ }^{27}$ Most South American countries devote less than $2 \%$ of their total health budget to mental health.

Whatever little money is available is further reduced by massive corruption, poor governance and gross mismanagement-factors endemic in most developing countries.

\section{Primary and mental healthcare}

Public funded primary health-care facilities are not well established in developing countries. ${ }^{1}$ Government run 
primary health-care facilities are poorly staffed and poorly run. Many lack basic essential drugs and are accessed only by the poorest of the society. There is no system of referral to secondary or tertiary care. The 'gatekeeper' role that primary health-care facilities play in developed countries does not exist in developing countries.

For example, in Pakistan most health care is out-ofpocket expenditure and people are free to approach secondary or tertiary care directly. Every person who can afford it seeks private medical care. Similarly, as primary care physicians give fee-for-service, it is not in their interest to 'lose' patients by referring them to specialists. In India $87 \%$ of the health-care cost is borne privately. ${ }^{1}$

With such a disparate and poorly established primary care system, it would be unrealistic to expect mental health care or suicide prevention programmes to be linked to primary health care or to succeed in any coherent way.

Similarly, mental health services in most developing countries are poorly developed. The mental health professional to population ratio is extremely low with one psychiatrist to a million people - in some sub-Saharan African countries it is one psychiatrist to 5 million people. Also, most psychiatrists are located in large urban centres while the majority of the population lives in rural areas, devoid of any access to mental health facilities.

\section{DEVELOPING COUNTRIES: SUICIDE PREVENTION}

How then can the problem of suicide be addressed in developing countries, given the serious lack of resources and low priority given to mental health? There are no easy answers but in the following section possible solutions are suggested.

\section{Managing DSH}

WHO estimates for every suicide there are at least 10-20 DSH acts. ${ }^{1}$ By this estimate, in China there would be between 2.8 million and 5.6 million; in India 1-2 million; in Sri Lanka 50000 and 100000 and in Pakistan between 30000 and 60000 DSH. Data from many developing countries is lacking but clearly people who carry out DSH acts form a pool from which many of future suicides are recruited. While the medical management of DSH is important and needs attention, the underlying psychological issues are rarely addressed. An excellent opportunity to engage the potential future suicide is therefore lost. In a study from India, 13\% of 269 suicides had made at least one previous attempt but $82 \%$ of these had not received any care. ${ }^{28}$

There is need for every DSH subject to undergo a psychiatric evaluation and be offered psychological help, no matter how innocuous the act may appear. Emergency room personnel in developing countries need to be trained in both medical and psychiatric management of DSH cases.

\section{Controlling methods of suicide}

Controlling access to common methods has been found to effect suicide rates. In the developing world ingestion of pesticides is one of the most common methods for committing suicide. ${ }^{29}$ In Western Samoa, a small Pacific island nation, the use of paraquat, a highly toxic herbicide was linked to rising suicide rates-from 6.1/100000 in 1971 to $31.1 / 100000$ in 1981 . This fact was widely publicized in a social-educational campaign on suicide prevention undertaken across the island. Subsequent rates showed a dramatic decrease. ${ }^{30}$

\section{Window of opportunity}

There is invariably an interval between onset of suicidal thoughts/ideation and the act of suicide, which may vary from hours to days and weeks. In developing countries this is frequently overlooked - partly because of ignorance but also because families and subjects do not know where to seek help. Even when they do realize something is wrong, they lack resources to seek help. In India only 24 of 269 suicide victims had been in contact with a mental health professional or family physician or were on treatment before the suicide. ${ }^{28}$

Studies using the psychological autopsy studies from India, China and Taiwan have shown that majority of suicides suffer from mental illness, of which depression is the most common disorder. ${ }^{6,19,20}$ With better mental health services depression can be treated successfully. A number of studies have shown the effectiveness of both pharmacological and psychological therapies in developing countries such as India, ${ }^{31}$ Pakistan, ${ }^{32}$ Chile $^{33}$ and Uganda. ${ }^{34}$

\section{Targeting young married women}

There is urgent need that any programme of suicide prevention in developing countries must address the high prevalence of psychological distress in young married women. Issues of early marriage, pressure to have children (especially a male offspring) early in the marriage and domestic violence are factors that correlate strongly with suicidal behaviour in young married women in developing countries.

\section{Need for review of the law}

In many developing countries, especially Islamic countries, suicide and DSH are illegal acts. Although prosecution is rare, the act is frequently exploited by the police in order to blackmail the victim and his/her family and extort money 
from them. ${ }^{9}$ Whatever deterrent value the law may have had appears to have lost its utility, as evidenced by the rising rates in countries like Pakistan.

Such laws need to be reviewed and, where possible, repealed. This would help families and hospital to seek help for the survivors of an attempt without the fear of being persecuted by the legal authorities. It would also help in the diagnosis and registration of suicides, leading to more accurate estimation of the problem.

\section{SOCIAL POLICIES}

Many developing countries have social policies that do little to alleviate the suffering of the masses. Poverty, unemployment, illiteracy, lack of civic facilities, poor access to health facilities, the absence of health insurance or of welfare are factors that adversely impact upon the overall mental health status of the population. In Pakistan and India, almost $50 \%$ people live below the poverty line, though both countries are nuclear powers. Governments in developing countries must strive to reduce this enormous disparity and introduce social policies that are fair, just and equitable and which would address the real problems of the people.

\section{THE NEED FOR MORE RESEARCH}

There is paucity of research on suicide from developing countries. Very little is known about suicides in many Middle Eastern, African and South American countries. Without good robust information, prevention programmes cannot be developed.

One way forward could be to establish regional centres for suicide monitoring and surveillance, given the many commonalities in culture, social and economic conditions in different regions such as South Asia, Africa, and South America. Sharing and exchanging information and research findings amongst nations with similar findings could be mutually beneficial.

There is also need for more and better information on suicidal behaviour in developing countries. Data collection at district, provincial and national levels needs to be developed. The information can be used for analyticalepidemiological studies of the characteristics of high-risk groups and the changes in those characteristics that take place over time. It should be made mandatory for all developing countries to report their mortality data on suicide to the WHO. This would improve the diagnosis of suicidal deaths.

\section{DEVELOPING COUNTRIES: THE CHALLENGE OF SUICIDE PREVENTION}

More than a decade ago, Diekstra (1993), ${ }^{35}$ the eminent Dutch suicidologist stated 'the most dramatic increase in suicide mortality in the next decades will be observed not in the developed world but rather in the developing countries. The most potent socio-economic \& behaviour factors of suicide risk are already present in a degree considerably higher than in many of the industrialised countries \& this discrepancy will probably only continue to grow'.

It is a sad indictment of our times that despite significant advancements in science and technology and of material wealth, a million potentially preventable deaths occur annually in this the 21 st century. Clearly, suicide prevention will continue to pose as big a challenge for the foreseeable future as it did 50 years ago. This is particularly so for developing countries, where lack of resources, poorly established primary and mental health services and weak political processes make prevention efforts doubly difficult.

Suicide prevention in developing countries poses a unique and formidable challenge. Public and mental health professionals as well as government and non-governmental organizations need to work together to take up this challenge.

\section{REFERENCES}

1 World Health Organization. The World Health Report 2001. Mental Health: New Understanding, New Hope. Geneva: WHO, 2001

2 Wilson JF. Finland pioneers international suicide prevention. Ann Intern Med 2004;140:853-6

3 World Health Organization. Mortality Database. Geneva. WHO, 2003 [www.who.int/mental_health/prevention/suicide/suiciderates/en/]

4 Department of Health. National Suicide Prevention Strategy For England. London: DoH, 2002

5 Bertolote JM, Fleischmann A. A global perspective on the epidemiology of suicide. Suicidologi 2002;7:6-8

6 Phillips MR, Li X, Zhang Y. Suicide rates in China, 1995-99. Lancet 2002;359:835-40

7 Girdhar S, Dogra AT, Leenaars A. Suicide in India, 1995-1999. Arch Suicide Res 2003;7:389-93

8 Mello-Santos CD, Bertolote JM, Wang YP. Epidemiology of suicide in Brazil (1980-2000): characterization of age and gender rates of suicide. Rev Bras Psiquiatr 2005;27:131-4

9 Khan MM, Prince M. Beyond rates: the tragedy of suicide in Pakistan. Trop Doct 2003;33:67-9

10 Ndosi NK, Mbonde MP, Lyamuya E. Profile of suicide in Dar es Salaam. East Afr Med J 2004;81:207-11

11 Nwosu SO, Odesanmi WO. Pattern of suicides in Ile-Ife, Nigeria. West Afr J Med 2001;20:259-62

12 Dong X, Simon MA. The epidemiology of organophosphate poisoning in urban Zimbabwe from 1995 to 2000. Int J Occup Environ Health $2001 ; 7: 333-8$

13 Kinyanda E, Hjelmeland H, Musisi S. Negative life events associated with deliberate self-harm in an African population in Uganda. Crisis 2005;26:4-11

14 Kebede D, Alem A. Suicide attempts and ideation among adults in Addis Ababa, Ethiopia. Acta Psychiatr Scand 1999;397(Suppl):35-9

15 Mabrouk AR, Omarb NM, Massoud K, et al. Suicide by burns: a tragic end. Burns 1999;25:337-9 
16 Gali BM, Na'aya HU, Adamu S. Suicide attempts in HIV/AIDS patients: report of two cases presenting with penetrating abdominal injuries. Niger J Med 2004;13:407-9

17 Islam MN, Islam MN. Pattern of unnatural death in a city mortuary: a 10-year retrospective study. Legal Med 2003;5:S354-6

18 Saeed A, Bashir MZ, Khan D, et al. Epidemiology of suicide in Faisalabad. J Ayub Med Col, Abbottabad 2002;14:34-7

19 Cheng AT. Mental illness and suicide. A case-control study in east Taiwan. Arch Gen Psychiatry 1995;52:594-603

20 Vijayakumar L, Rajkumar S. Are risk factors for suicide universal? A case-control study in India. Acta Psychiatr Scand 1999;99: 407-11

21 Ahmed MK, Ginneken JV, Razzaque A, et al. Violent deaths among women of reproductive age in rural Bangladesh. Soc Sci Med 2004;59:311-19

22 Kumar V. Poisoning deaths in married women. J Clin Forensic Med $2004 ; 11: 2-5$

23 Mumford DB, Saeed K, Ahmad I. et al. Stress and psychiatric disorder in rural Punjab. A community survey. Br J Psych 1997;170: 473-8

24 Patel V, Araya R, de Lima M, et al. Women, poverty and common mental disorders in four restructuring societies. Soc Sci Med 1999;49:1461-71

25 Aaron R, Joseph A, Abraham S, et al. Suicides in young people in rural southern India. Lancet 2004;363:1117-18

26 Vizcarra B, Hassan F Hunter, et al. Partner violence as a risk factor for mental health among women from communities in the
Phillipines, Egypt, Chile and India. Inj Control Saf Promot 2004; 11:125-9

27 Social Policy and Development Center. Social Development In Pakistan: Annual Review 2000. Karachi: Oxford University Press, 2001

28 Gururaj G, Isaac MK, Subbakrishna, et al. Risk factors for completed suicides: a case-control study from Bangalore, India. Inj Control Saf Promot 2004;11:183-91

29 Gunnell D, Eddleston M. Suicide by intentional ingestion of pesticides: a continuing tragedy in developing countries. Int J Epidemiol 2003;32: 902-9

30 Bowles, J. Suicide In Western Samoa: An Example of a Suicide Prevention Program In a Developing Country. Leiden: Brill, 1995

31 Patel V, Chisholm D, Rabe-Hesketh S, et al. Efficacy and costeffectiveness of drug and psychological treatments for common mental disorders in general health care in Goa, India: a randomised, controlled trial. Lancet 2003;361:33-9

32 Ali B, Rahbar M, Naeem S, et al. The effectiveness of counseling on anxiety and depression by minimally trained counselors. Am J Psychother 2003; 57:324-36

33 Araya R, Rojas G, Fritsch R, et al. Treating depression in primary care in low income women in Santiago, Chile: a randomized controlled trial. Lancet 2003;361:995-1000

34 Bolton P, Bass J, Neugebauer R, et al. Group interpersonal psychotherapy for depression in rural Uganda: a randomized controlled trial. JAMA 2003;289:3117-24

35 Diekstra RF. The epidemiology of suicide and parasuicide. Acta Psychiatr Scand 1993;371(Suppl):9-20 